\title{
Industrial College: A study of new models of engineering and technology talent training
}

\author{
YIN LU \\ College of Biology and Environmental Engineering, Zhejiang Shuren University, CHINA \\ BINGYAN LI \\ College of Biology and Environmental Engineering, Zhejiang Shuren University, CHINA \\ TIAN TIAN \\ College of Management, Zhejiang Shuren University, CHINA
}

\begin{abstract}
The introduction of 'Industrial College' constitutes a supply-side structural reform in which higher education actively adapts to the industrial revolution and technological development to build academic subject clusters. This article explores the new organizational form of industrial colleges from the point of view of four aspects: history and origin, connotation and essence, form and model, and international experience. Second, it analyses the significance of cultivating practical engineering and technology talents in industrial colleges from application value and theoretical significance. Third, it suggests improving the organic circulation of four chains, including standard chain, institutional chain, goal chain, and information chain, and gradually forming the guarantee system of 'setting standards - implementation process - monitoring results - feedback \& evaluation'. Fourth, it expects to activate and strengthen the ability of universities to integrate regional industrial technology innovation and transformation, by reinforcing the exploration of the construction path for collaborative education and demonstrating the construction of the industrial college.
\end{abstract}

Key-Words: - Leave one blank line after the Abstract and write your Key-Words (6 - 10 words) Industrial College; application-oriented undergraduate program; engineering education; technology talent training

Received: November 2, 2019 Revised: March 30, 2020. Accepted: April 24, 2020. Published: May 5, 2020.

\section{Introduction}

The primary task of higher education is talent training. In the 'National Medium and Long Term Education Reform and Development Plan (20102020)', talents are divided into academic, practical, and mixed type, and an 'application-oriented' talent training strategy has been clarified for the first time, stated as a "new mechanism for joint training of talents between universities and research institutions, industries, and enterprises'. In 2015, the Ministry of Education and others jointly published the 'Guiding Opinions on Instructing Applicationoriented Transformation of Local Undergraduate Colleges' to promote the transformation and development of some local undergraduate colleges, and to further clarify the primary tasks of transformation and development, such as 'taking the integration of production and education and cooperation between colleges and enterprises as a breakthrough', 'building a cooperation development platform for industries and enterprises', 'establishing a professional system connecting industry chain and innovation chain closely', and 'innovating a talent training model of collaborative education'. In 2017, the State Council issued
'Several Opinions on Deepening the Integration of Production and Education', which proposed to 'deepen the integration of production and education and to promote the organic connection between the educational chain, talent chain, industry chain, and innovation chain'. The policy of supply-side structural reform of human resources emphasizes the role of industry and enterprises in the process of running colleges and 'leading enterprises into colleges and education', thus fully promoting the collaboration in education between colleges and enterprises.

The training of practical engineering and technology talents differs from academic (research) and mixed (skilled) talent training. Under the new supply-side structural reforms of Chinese undergraduate education, in the early stages of industry-oriented colleges, the aim is to transform general undergraduate education to applicationoriented undergraduate education. These colleges function as authoritative 'demonstration sites' for the new application-oriented undergraduate university model, created through a transformation of general undergraduate colleges; they reflect three advantages: effectively docking industry needs, 
practising the transformation development of 'new engineering', and activating and strengthening the integration of universities with regional industrial technology innovation and transformation [1].

In this commentary, we consider how strengthening partnerships between academic and industrial institutions can help provide a workforce skilled in engineering education. Our discussion is organized around a few key questions. The first asks what is Industrial College? Second, how to develop Industrial College to help young scientists acquire the skills needed by their future employer under academic-industrial partnerships?

\section{The Connotation and Model of Industrial College}

\subsection{The history and origin of Industrial College}

Looking back at the history of China's higher education development, one finds that the rise of industry-oriented colleges preceded the emergence of general universities. The Fuzhou Ship Management Academy and the Telegraph School in the late Qing Dynasty of China, as well as the Engineering College and Textile College in the Minguo era, are early examples of professional training institutes. Further, when the People's Republic of China was newly established, higher education universities relied on industry and industrial talent training in the form of 'Each industry runs a class of schools' for higher education development [2]. The industrial training college, under the background of new engineering, is a secondary school subordinated to and built under the 'New University' and co-managed by the industry and enterprises [2]. The industrial college not only breaks the absolute dependence on industry but also makes full use of the comprehensive subject advantages of higher education to provide more flexible and comprehensive talents for the development of the industry. Therefore, the industrial college reflects a supply-side structural reform of higher education that actively adapts to the industrial revolution and technological development to build a subject cluster.

\subsection{The Connotation and Essence of Industrial College}

The fundamental framework of industrial colleges includes industry title, industry location, and type of cooperation (i.e., college-enterprise integration, college-enterprise orders, college-industry cooperation, college-local government cooperation, and alliance between colleges and associations) [3]. In an attempt to innovate through collaborative education the industrial college integrates undergraduate colleges and industries (or key and typical enterprises in the industry) [4]. It aims at the industry (enterprise), with clients and the production chain, product chain, technology chain, and service chain as targets, functioning as a secondary college that develops application-oriented undergraduate universities through the participation of industry and enterprises in the running of universities [5-9]. The model of the industrial college has become a means of practical talent training in universities based on a cooperation between teachers and industry experts in a real industry (enterprise) environment [10].

\subsection{The form and model of Industrial College} Following an analysis of cooperation factors, the industrial college can be divided into three types: integration, chain, and multipoint integration [11]. From the perspective of cooperation partners, the industrial college can also be divided into collegeenterprise orders, college-enterprise integration, college-local government cooperation, collegeindustry cooperation, an alliance between colleges and associations, and a multi-partner integration with direct government involvement [3]. In terms of functions, the industrial college can be divided into resource sharing, joint development, and industryleading models, among which resource sharing is a low-level cooperation model focusing on talent and platform resource sharing [12]. Based on resource sharing, joint development aims at enhancing the strength or competitiveness of all parties by promoting a development for all. Industry-leading means that the cooperation partners will lead the development at a strategic level to deepen the cooperation in terms of industry standards and critical technologies. These three types indicate the progression stages of development of industrial colleges.

Additionally, there are differences in cooperation subjects in industrial colleges, between single subject or subject clusters and single enterprise, industry clusters, or industry chain. Thus, based on the actual situation, a variety of forms and models of the industrial college (see table 1) are generated, based on local conditions, by considering cooperation elements, cooperation partners, college function, and cooperation subjects. For example, an Industrial College adopts the A1B2C3D12 model, which shows that the cooperation between universities and enterprises has the characteristics of resource sharing, chain type, school local cooperation, involving more professional masses, 
etc. From the perspective of collaborative education, application-oriented undergraduate colleges, as the main body of the industrial college, designed according to functions in the talent training model, teaching practice environment, the construction of professional subjects and practical teaching staff, and the development of practical technology research. The governance structure of the industrial college is thus produced according to its objective conditions, and the scientific community defines its organizational characteristics and establishes corresponding operating models and safeguard mechanisms [13].

Table 1 - Forms and models of Industrial College

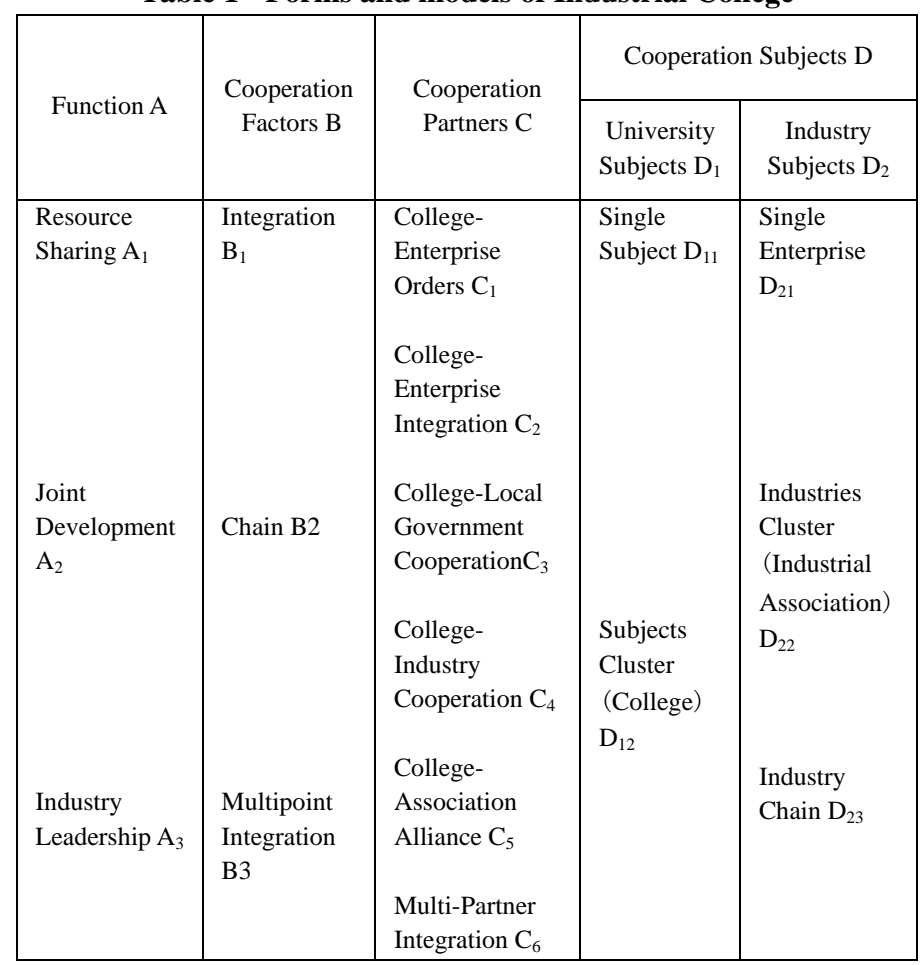

\subsection{International experience of Industrial Colleges}

The concept of college-enterprise joint education was first developed in the United States in the first half of the 19th century. It includes American 'collaborative education', British 'Sandwich' education, Japanese 'Production-Learning Cooperation', German 'Dual System', Australian 'TAFE' model, French 'Apprenticeship Training Centre', and Singaporean 'Teaching Factory' training model [14]. In particular, engineering education in the United States and Germany maintained a strong development momentum, which facilitated the development of engineering in both countries. For example, the National Academy of Engineering and the American Research Council jointly published a research report entitled
'Engineering in K-12 Education: Understanding the Status and Improving the Prospects', which specifically discussed 'the concept of engineering education and capabilities, the implementation state of engineering education, the topic of engineering teaching, and improvements of engineering methods' [15,16]. Kruno Hernaut [17] discussed the Bologna declaration and the establishment of the European higher education area, focussing on the state and development trend in the field of engineering education in Germany and European countries. Because of the lack of a corresponding social system and the infiltration of social culture, the domestic community is difficult to ensure the sustainable development of transplanting the college-enterprise cooperation model from overseas application-oriented universities.

\section{Construction Strategy of Industrial College of Application-oriented Undergraduate Colleges under the Circumstance of New Engineering}

According to the new requirements of national strategic development, the new situation of international competition, and the new impetus of economic development, the construction of 'New Engineering' is a major strategic choice for higher engineering education reform [18]. However, the current engineering education system in the vast number of application-oriented undergraduate colleges accounts for $90.8 \%$ of the total number of national ordinary universities and colleges, which is problematic in terms of fixed development logics, lack of collaborative college-running mechanisms, and barriers of organizational systems [19]. This deeply limits the construction of 'New Engineering'. Therefore, application-oriented universities should focus on the orientation of college-running and the development of regional industries to effectively break down barriers in the subject and explore a new training strategy for engineering and technology talents. This is the key to improving the core competitiveness of college services and establishing the characteristics of college-running. As an innovative mechanism and model of college-local government and collegeindustry coordinated practical talents training, the industrial college not only inherits the advantages of cooperation among industry, colleges, and research institutes but also highlights the upgradation and transformation of application-oriented undergraduate colleges, consciously building a new sustainable engineering talent training system down to earth, integrating industry, and focused on 
application. The ' 40 Sections of Higher Education in New Age' also clearly states that it is necessary to deepen the integration of resources and construct a collaborative education mechanism with comprehensive integration for cultivating high-level practical talents. The industrial college, marked by college-enterprise coordination, is becoming an irreplaceable new model in training engineering and technology undergraduate talents.

\subsection{The significance of Industrial college in cultivating practical talents of engineering technology}

\subsubsection{Application value}

Practical talents of engineering technology serve as an emerging force and an intelligence source in the construction of local economy and society. To match the output of application-oriented undergraduate colleges with the demand of local industries and enterprises not only encourages universities to fulfil the roles of talent cultivation, scientific research, social service, cultural inheritance and innovation, but also facilitates local economy and industries to effectively allocate the discipline resources and layout of higher education according to the development trend; this conforms to the Guideline on Application-oriented Transformation of Some Local Universities and Colleges. Industrial colleges break the limitation of traditional professional schools to serve as the leader in transforming traditional engineering programs. They make use of external force to expand development space and formulate a mutually beneficial and complementary model featuring 'four introductions' of universities (i.e. capital introduction, intelligence introduction, policy introduction, and industrial standard introduction) and 'four gains' of local industries (i.e. gain economic benefit, gain technical engineering service, gain professional training, and gain reserve talents) [20]. In this way, they will gradually overcome the barriers against cultivating local practical talents of engineering technology, i.e., resource constraints, discipline barriers, and lack of communication between schools and enterprises. Consequently, the organic connection of the educational chain, talent chain, industrial chain, and innovation chain will be strengthened, and a new model of collaborative talent cultivation will be established.

\subsubsection{Theoretical significance}

The industrial college model is a key solution to the challenge faced by application-oriented undergraduate education in China, i.e. the establishment of a system for cultivating high-level engineering talents. Under the new educational architecture, emerging industrial colleges have evolved beyond the original responsive problemsolving model. Based on a three-fold system composed of industrial demands, educational rules, and university student development, this model has widened the research perspective of organizational theories such as the rules and norms of cultivating engineering talents. This model comprehensively reveals the mechanism and path of industrial colleges as media to promote collaborative talent cultivation and promotes in-depth analysis on the organization support system, rule support system, culture support system, and quality-guaranteeing mechanism for talent cultivation. This helps to expand the vision and cognitive space for theoretical research, which exempts industrial colleges from the limits of innate factors such as geographical conditions, school history, industrial background, and disciplinary foundation to become real existences ready for duplication and promotion. Furthermore, it also provides crucial theoretical support and shapes policy design for education by exploring the development strategy of "making the interactive collaboration between industrial colleges and traditional professional schools the key pivot for improving the quality of practical engineering technical talents in cultivation' [4].

\subsection{Key 'four chains' in the implementation of Industrial Colleges}

In the process of cultivating engineering technical ability, the education model of universities as the only subjects features a lack of coordination with industrial development and a mismatch between supply and demand. Consequently, applicationoriented undergraduate colleges have been dedicated to the so-called New Engineering Education Transformation (NEET). Specifically, they work on improving the organic circulation of four chains: standard chain, institutional chain, goal chain, and information chain. Accordingly, they logically pre-set four questions, i.e. 'how to measure quality', 'how to guarantee quality', 'how to focus on quality', and 'how to account for quality', and gradually form a virtuous circle of the qualityguaranteeing system in talents cultivation, which involves 'setting standard - implementation process - monitoring results - feedback \& evaluation’. 


\subsubsection{Standard chain}

Reshaping the standard chain that consists of a national professional standard - industrial employment standard - quality standard of university talent cultivation is pivotal to solving the problem of 'how to measure quality'. The quality standard of cultivating practical talents of engineering technology is a benchmark for evaluating the effectiveness of engineering education as well as a behavioural framework to regulate the engineering educational activities of industrial colleges. It serves as an essential condition for guaranteeing the quality of engineering talent cultivation and the foundation of engineering education at universities and colleges, reflecting the basic value pursuit of engineering education quality in industrial colleges [21]. The first level of talent cultivation is academic quality standard, which includes not only academic qualification standards, i.e., degree and diploma, of all types and levels in engineering education but also the quality specifications of different levels in the disciplinary domain and the professional domain. On the second level, faced with the challenges from the new industrial revolution, the quality standard encourages industrial sectors to establish evaluation standards of talent cultivation according to national standards (i.e., ' 30 Suggestions on Improving the Quality of Higher Education') in order to transform from a scientific paradigm to an engineering paradigm. Last but not least, higher education institutions of engineering should establish quality standard systems with identifiable goals and customized characteristics, and clarify the knowledge systems, abilities, and values that academic qualification holders acquire.

\subsubsection{Institutional chain}

To clarify 'how to guarantee quality', it is key to reshape the institutional chain made up of organizational institution - governing system administrative mechanism based on the original organization and management institutions of teaching at application-oriented undergraduate colleges. When the educational chain, the talent chain, the innovation chain, and the industry chain are organically associated to form a system of coordinative innovation, it is necessary to provide support for heterogeneous resources with corresponding organization structures and systems, while also sharing and integrating knowledge and information to facilitate mutual development [22]. To ensure that industrial colleges successfully implement these elements in the running of the school, the following measures should be followed. In terms of the organization and institutional system, introduce diversified subjects to the board of directors and implement the dean responsibility system under the leadership of the board to establish a cooperative governing model (talent cocultivation, process co-management, results-sharing, and responsibility-sharing). In terms of the governing system, one should establish a governing structure that combines the modern system of property rights with the modern school system to promote industrial colleges to transform from unitary and vertical administrative governance to horizontal network governance. In terms of management mechanism, one should learn from the operation mechanism of enterprises to guarantee the deal with autonomous rights in institutional setup, personnel evaluation, management, resource allocation, etc. Moreover, establishes a competitionincentivized evaluation system based on market principles.

\subsubsection{Goal chain}

The premise of analysing 'how to focus on quality' is to ensure that process monitoring continues throughout the cultivation of engineering talents, as well as to reset the goal chain that comprises quality monitoring points - evaluation subjects - expected goals comparison. The generation, application, and transmission of knowledge in industrial colleges is scenario-based and application-oriented and includes multiple types of subjects [23]. This determines that the quality monitoring of industrial colleges will transform from closeness to openness. In terms of the setup of quality monitoring points, one should closely combine the goal chain with industry clusters and industrial chains. The course system should be application-oriented, and the faculty construction should concentrate on training teaching staff in both theory and practical application and improving the conversion rate of scientific and technological achievements. In terms of cultivating student ability, it is important to pay more attention to practical application. In terms of evaluation subjects, the tradition of peer review should be forwarded to the stakeholder and the 3rd party review in order to satisfy the demands of the market and the industry. In terms of expected goals of talent cultivation, the 'Four Must' standard can be discarded; valuing instead, students' core competence in the job market, especially the ability to solve complicated technical and social problems, and gradually integrate the goals with internal 
quality control so as to ensure a virtuous circle of educational activities.

\subsubsection{Information chain}

Reconstructing an information chain consisting of information platform - collecting information flow - processing information classification - feedback and evaluation according to the data needs of colleges, society, industry, and enterprises is the foundation for understanding 'how to account for quality'. In other words, helpful information is the core of the teaching quality management system. First, feedback from students (direct perceivers of teaching quality) allows colleges to closely observe the teaching objectives, and making adjustments in time ensures a more rational teaching process. Second, feedback from industry and enterprises (employers of higher education talents) indicates the width and depth of talent ability training for colleges, which help to fill in the gap between educational supply and social demand. Last but not the least, feedback from society means that the industrial college establishes a social sharing system of relevant teaching resources to expand its social influence under communal supervision [24]. Therefore, education quality follows a virtuous cycle of an information chain composed of evaluation-feedback-improvement-re-evaluation.

\subsection{Preliminary results of Industrial College exercise based on virtual internships}

In the fall of 2017, we implemented educational concept of Industrial College in a new first-year undergraduate course at Zhejiang Shuren University. The course enrolled 50 students: half the students $(n=25)$ were randomly selected to participate in Industrial College, and the other not. This crossover study design effectively doubles the sample size because each student serves as both a treatment case and a control case. All students completed all activities in both simulations. Data were collected from pre- and postsurveys integrated into each simulation.

\subsubsection{Result 1}

Experience with an Industrial College internship leads to more advanced engineering thinking. The results of epistemic network analysis (ENA) [25] performed on two groups of students in the internship are shown in Fig.1. Students in one group were evaluated without any prior experience with an engineering internship; students in the other group have courses of Industrial College before. The two groups were significantly different on the second dimension $($ mean $\mathrm{A}=0.301$, mean $\mathrm{B}=0.159 ; \mathrm{p}=0.002$, $\mathrm{t}=3.266$, and Cohen's d=0.369). Each point in Fig.1 is the centroid of a student's epistemic network. To determine which elements account for the difference between the two groups, we compared their mean epistemic networks. Students using an engineering internship for the first time had a higher mean on dimension two because those students made connections mostly among basic skills and knowledge. Students who had already participated in a previous Industrial College courses made additional connections with epistemological elements of engineering and knowledge of the client, elements that are indicative of thinking like an engineer.

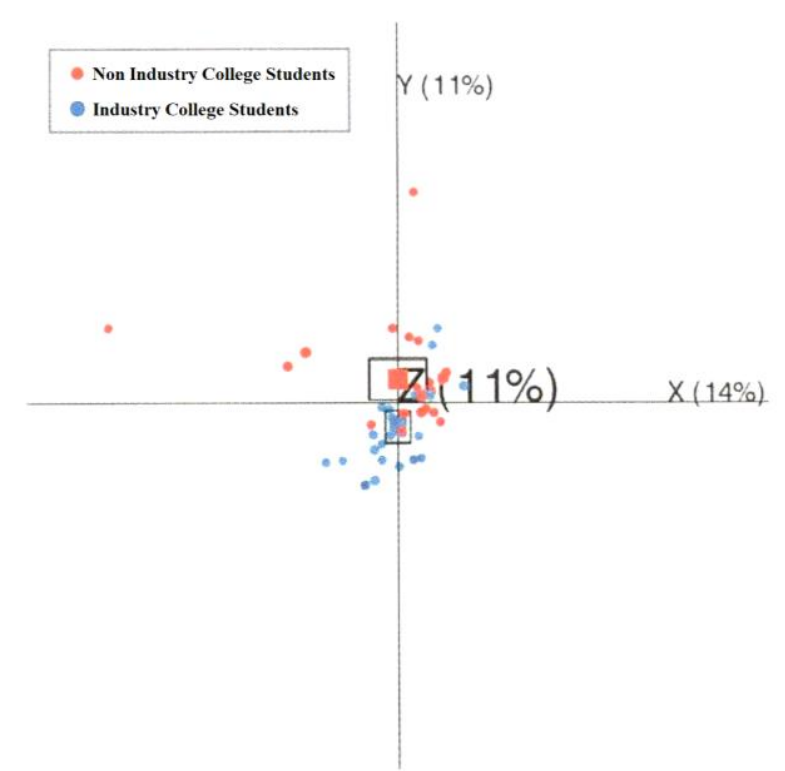

Fig.1 - ENA scatterplot showing two groups of students who were evaluated by the virtual internship. One group had no prior exposure to an engineering internship (non-Industrial College student). The other group have engineering internship prior to evaluation (Industrial College student). The points are individual students; the squares are the means for the two groups; the boxes are the $95 \%$ confidence intervals. The numbers in parentheses indicate the percentage of variance in the data accounted for by that dimension.

\subsubsection{Result 2}

Experience with an Industrial College Internship increases student satisfaction. At the conclusion of each internship, students were asked to evaluate their experience (free response), and student responses were coded as positive, negative, or mixed/neutral. Student satisfaction with the course was predominantly positive, and no students felt that their experience was negative. Furthermore, the proportion of positive responses increased after students had courses of Industrial College, and the proportion of neutral or mixed responses decreased. 


\section{Conclusion}

In conclusion, application-oriented undergraduate colleges have become hubs of regional practical talents in the form of industrial colleges and constitute a high value-added and comprehensive competitiveness advantage in the process of crossborder college-running, which has effectively changed the competitive environment of application-oriented undergraduate colleges. To significantly enhance the vitality of industrial colleges and fully realise its leading role in reforming higher education, it is necessary to adhere to the theme of construction strategy by improving the organic cycle of the standard chain, institutional chain, goal chain, and information chain. Further, steps should be taken to realize the 'Six Joints' -the joint building of governing methods, joint development of training programs, joint construction of teaching teams, joint promotion of management reform, joint building of industryacademia-research collaboration bases and joint conduct of project research and development and to construct the real 'community with a shared future for college-enterprise' [26].

Bloom proposed the taxonomy of thinking skills [27]. The thinking skills are defined at six levels, specified as Level 1 (remembering), Level 2 (understanding), Level 3 (applying), Level 4 (analysis), Level 5 (evaluation) and Level 6 (creating). The first three levels are generally classified as low order learning skills and next three levels are often referred as critical thinking/higher order skills. American Board of Engineering and Technology (ABET) [28] enlists that curriculum should be aligned to the specified undergraduate attributes. The alignment of undergraduate attributes mandates that the Teaching Learning Process be designed to be Outcome Based as enshrined in the objectives of Outcome Based Education (OBE). The Washington Accord [29] and other National Protocols like National Board of Accreditation (NBA) [30] have stressed the need for OBE in engineering spectrum. The OBE necessitates the implementation of all levels of Bloom's Taxonomy in the teaching-learning process as applicable to engineering education to achieve the resultant outcomes. The present System of teaching the courses using only the "Chalk and Talk" method does not afford enough time to implement all levels of Bloom's Taxonomy. At the maximum, only the first three levels can be implemented. The teachers are finding it difficult to apply next three levels due to the paucity of time. As a result of this, the students are being denied exposure to critical thinking/ higher order skills, thus adversely impacting the important outcomes. The mode of Industrial College would help Engineering education coupled with Chalk and Talk method, and allow the implementation of all levels of Bloom's Taxonomy in the engineering curriculum thus fulfilling the objectives of OBE can be possible. It also makes online engineering education possible.

Engineering education is a broad field of study, replete with its own cultural value system and ways of conducting research. It is probably reasonable to suggest that the prevailing research paradigms in engineering education are largely characterized by deductive-nomothetic, phenomenological, and critical perspectives. Many research, evaluation, and assessment pursuits in engineering education target interaction-dominant phenomena. These methods don't serve to replace existing research traditions and paradigms, but rather complement them by providing new insights and forms of evidence that can be used for improved understanding and decision making [31]. There are a variety of domains where the theory of Industrial College can provide new insights and ways of thinking about research. Naturally, the paper has some limitations. It does not cover the full spectrum of the development of Industrial College. The theory has not yet been fully tested on its suitability and capability with emerging engineering education paradigms. It is expected that the findings of this research can be a useful reference contributing to future research or engineering education and training.

\section{Acknowledgements}

The authors of this study express their gratitude to the MOE (Ministry of Education in China) Project of Humanities and Social Sciences (No. 18JDGC034), the New Engineering Research and Practice Projects of the Ministry of Education, and the Philosophy and Social Science Foundation of Zhejiang Province (No. 18NDJC272YB) for financial supports of this study.

\section{Declaration of Conflicting Interests}

The authors declared no potential conflicts of interest with respect to the research, authorship, and/ or publication of this article.

\section{References:}

[1] Sun, B.Z., and Gong, S., Industrial College: Transitional Development from Form to Soul Reshaping, Educational Review, Vol.12, 2016, pp. 14-17. 
[2] Liu, Y.R., and Liao, W.Q, New-type University: What the 'Type' Is, Chongqing Higher Education Research, Vol.5, 2017, pp. 17-29.

[3] Li, B.Y., Tang, F.L., and Zheng, X.M., Functional Design and Operation Model of Industrial College, Educational Review, Vol.11, 2015, pp. 3-6.

[4] Zhu, L.Z., Cultivation of Interactive and Innovative Applied Talents in Schools and Areas, China Higher Education, Vol.15, 2016, pp. 21-23.

[5] Zhu, L.S., and Sun, J.J., Industry College Model: New Exploration of Applied Talents Training in Newly-built Undergraduate Colleges, University (Academic Edition), Vol.12, 2012, pp. 18-23.

[6] Chen, X.M. Industry Colleges: A New Form of Transition and Development of Local Undergraduate Colleges and Universities, Chinese Journal of Social Sciences, 2017.

[7] Xu, X.Q., Jin, J.B., and Zhou, C.C., Industry College: Concept Connotation, Organizational Characteristics and Practical Paths: On the Cultivation of Applied Talents in Nongovernmental Regular Universities, Journal of Zhejiang Shuren University, Vol.18, 2018, pp. 1-6.

[8] Sun, B.Z., Pilot Study on the Reform of Fujian University Industry College Under the View of Transitional Development, Educational Review, Vol.7, 2018, pp. 19-22.

[9] Olcomendy, L., Santos-Cessac, F., Dondon, $\mathrm{Ph}$., Design of a Low Cost LIDAR Scanning System for Didactical Applications, International Journal of Circuits, Systems and Signal Processing, Vol.13, 2019, pp. 366-372.

[10] Li, B.Y., Fang, X.B., and Chen, M.R., Functional Analysis and Construction Ideas of Industrial Colleges, Educational Review, Vol.9, 2017, pp. 14-17.

[11] Xu, Q.E., Industrial college: An Effective Exploration of Combining Work with Learning in Higher Vocational Colleges, Research on Higher Education in China, Vol.10, 2017, pp. 72-73.

[12] Zhu, W.H., and Peng, Y.F., Research on the Construction of Industrial College in Local Undergraduate Colleges and Universities under the Background of New Engineering, Journal of Higher Education Management, Vol.12, 2018, pp. 30-37.

[13] Li, Y.F., Organizational Characteristics and Operational Model of Industrial Colleges of
Local Universities, Prospects for Science and Technology, Vol.26, 2016, pp. 334.

[14] Lu, L., Practice Research on Cultivating Excellent Engineers by Coalition of Colleges and Enterprises-based on Local Applied Colleges and Universities, Chengdu: Sichuan Normal University, 2015.

[15] National Research Council, A Framework for K-12 Science Education: Practices, Crosscutting Concepts, and Core Ideas, Washington, DC: National Academies Press, 2012.

[16] Patrick, S., Kennedy, K., and Powell, A., Mean What You Say: Defining and Integrating Personalized, Blended and Competency Education, Vienna, VA: International Association for K-12 Online Learning, 2012.

[17] Krunor, H., Present Situation and Prospect of Engineering Education in Germany and Europe, Continuing Education, Vol.20, 2006, pp. 59-61.

[18] Lin, J., The Construction of China's New Engineering Disciplines for the Future, Tsinghua Journal of Education, Vol.38, 2017, pp. 26-35.

[19] Xia, J.G., and Zhao, J., On the Reform and Development of Engineering Education in Local Universities and Colleges Based on Establishing Emerging Engineering Education, Research on Higher Engineering Education, Vol.3, 2017, pp. 15-19, 65.

[20] Li, B.Y., and Lu, Y., Connect with Classic History Industry and Develop New Subject Education in a Cooperative Way, China Education Daily, 2018.

[21] Meng, F.Q., Zhu, H., Wu, X.D., and Li, Z.Y., The Strategy for the Construction of Talent Cultivation Quality Standards System in China's Engineering Education Faced with the 'New Industrial Revolution', Research on Higher Engineering Education, Vol.5, 2015, pp. 15-20.

[22] Hu, W.L., The Logic of the Organizational System Innovation in Industry College: In the Perspective of Three Chain Integration, Research on Higher Engineering Education, Vol.3, 2018, pp. 13-17.

[23] Hong, T.H., Le, T.V.N., Dinh, T.N.H., Luong, M.L., and Pham, M.D., The Quantified Analysis of Causes of Market Risk Fluctuations in the Group of Construction, Real Estate and Construction Material Companies in Vietnam during and after the Global Crisis 2007-2011, WSEAS Transactions on Environment and Development, Vol.17, 2020, pp. 75-84. 
[24] Ngo Chi Thanh, Nguyen Duy Dat, Nguyen Dac , Anh Chuong, and Dinh Tran Ngoc Huy., A Business Model for Producing Clean Energy in Developing Countries, WSEAS Transactions on Business and Economics, Vol.16, 2020, pp. 2224-3496.

[25] Nash, P., and Shaffer, D.W., Epistemic Trajectories: Mentoring in a Game Design Practicum, Instructional Sci., Vol.41, 2013, pp. 745-771.

[26] Pham Tuan Anh, Dinh Van Son, and Dinh Tran Ngoc Huy., The Quantified Analysis of Causes of Market Risk Fluctuations in the Group of Construction, Real Estate and Construction Material Companies in Vietnam During and After the Global Crisis 2007-2011, WSEAS Transactions on Environment and Development, Vol.16, 2019, pp.2224-3496.

[27] Clark, D., Bloom's Taxonomy of Learning Domains: The Cognitive Domain, Open Learning Environments, 2015.

[28] ABET, Criteria for Accrediting Engineering programs, www.abet.org/eaccriteria2014-2015, 2015.

[29] Washington Accord, www.ieagreements.org/washington-accord.

[30] National Board of Accreditation, nbaind.org./En/1051/-nbasaccreditationparameterscriteria-\& processors.aspx.

[31] Davis, B., and Sumara, D.J., Complexity and Education: Inquiries into Learning, Teaching, and Research, Psychology Press, 2006. 